\title{
Avaliação da resistência ao desgaste de aluminas nanométricas produzidas a partir da decomposição térmica de acetato de alumínio liofilizado
}

\section{(Evaluation of wear resistance of nanometric aluminas produced by thermal decomposition of lyophilized aluminum acetate)}

\author{
E. Fagury Neto ${ }^{1}$, R. H. G. A. Kiminami ${ }^{2}$ \\ ${ }^{1}$ Laboratório de Materiais Cerâmicos - LMC, Faculdade de Engenharia de Materiais, Universidade Federal \\ do Pará, Campus Marabá, Folha 17, Quadra 04, Lote Especial, Marabá, PA 68505-080 \\ ${ }^{2}$ Laboratório de Desenvolvimento e Processamento de Materiais em Microondas - LaDProM \\ Departamento de Engenharia de Materiais, Universidade Federal de S. Carlos \\ Rod. Washington Luiz, km 235, S. Carlos, SP 13565-905 \\ fagury@ufpa.br,ruth@power.ufscar.br
}

\begin{abstract}
Resumo
Ensaios de resistência ao desgaste, na modalidade pino-contra-disco com pares deslizantes, foram realizados em pinos confeccionados a partir de pós de alumina proveniente do processo de decomposição térmica de acetato de alumínio liofilizado. Pós de alumina referentes às fases $\alpha-\mathrm{Al}_{2} \mathrm{O}_{3}$ e $\gamma-\mathrm{Al}_{2} \mathrm{O}_{3}$, com e sem aditivos de sinterização $\left(\mathrm{MgO}\right.$ e $\left.\mathrm{La}_{2} \mathrm{O}_{3}\right)$, foram usados para confeccionar pinos de desgaste. Pinos feitos também a partir de alumina comercial (A1000 SG) foram analisados e os resultados foram comparados. Os ensaios foram feitos de acordo com norma ASTM e mostraram que os pinos confeccionados a partir de $\alpha-\mathrm{Al}_{2} \mathrm{O}_{3}$ têm elevada resistência ao desgaste, comprovada pelos ensaios de perda de massa e microscopia eletrônica. Os pinos de $\gamma$ - $\mathrm{Al}_{2} \mathrm{O}_{3}$ tiveram desempenho intermediário e os pinos de A1000 SG mostraram resultados menos expressivos.

Palavras-chave: resistência ao desgaste, alumina nanométrica, decomposição térmica.
\end{abstract}

\section{Abstract}

Wear resistance tests, using the pin-on-disk test method with sliding pairs, were carried out on pins produced from alumina powders prepared by thermal decomposition of lyophilized aluminum acetate. Alumina powders of $\alpha-\mathrm{Al}_{2} \mathrm{O}_{3}$ and $\gamma-\mathrm{Al}_{2} \mathrm{O}_{3}$ phases, with and without sintering additives ( $\mathrm{MgO}$ and $\mathrm{La}_{2} \mathrm{O}_{3}$ ), were used to produce wear pins. In addition, pins made of commercial alumina (A1000 $S G)$ were tested and the results compared. The tests, carried out according to the ASTM standard, indicated that the pins made with $\alpha-\mathrm{Al}_{2} \mathrm{O}_{3}$ powder showed high wear resistance, a finding corroborated by mass loss tests and scanning electron microscopy. The $\gamma-\mathrm{Al}_{2} \mathrm{O}_{3}$ pins showed an intermediary performance while the A1000 SG pins showed less interesting results.

Keywords: wear resistance, nanometric alumina, thermal decomposition.

\section{INTRODUÇÃO}

Estudos tribológicos têm sido largamente desenvolvidos por diversos grupos, para a ampla aplicação de cerâmicas como componentes resistentes a condições severas de desgastes em peças e equipamentos. Apesar das características frágeis dos materiais cerâmicos em relação aos metais, caracterizada pela baixa tenacidade à fratura, em aplicações tribológicas esta propriedade pouco importa. Materiais como $\mathrm{Al}_{2} \mathrm{O}_{3}, \mathrm{SiC}, \mathrm{Si}_{3} \mathrm{~N}_{4}, \mathrm{ZrO}_{2}$, entre outros, encontram utilidade como componentes de seções quentes de turbinas a gás, bicos queimadores, anéis de vedação, esferas de rolamento, próteses, etc. [1, 2].

Para materiais cerâmicos são estabelecidos dois regimes distintos de desgaste: suave e severo. Evidências colhidas na literatura indicam que, para efeito de desgaste, cerâmicas serão úteis como componentes tribológicos quando apresentarem valores de taxa específica de desgaste abaixo de $10^{-6} \mathrm{~mm}^{3} / \mathrm{Nm}$, que é o limite superior do modo suave de desgaste [3-5]. Contudo, embora de maior aplicação prática, o modo suave tem sido pouco estudado, e o conhecimento pleno do mecanismo ainda deve ser investigado a fundo. A maioria dos estudos trata da estrutura da superfície desgastada, em geral, na faixa de trabalho do modo severo, de pouca aplicação prática. Tais estruturas diferem daquelas formadas no modo suave, as quais mostram uma superfície alisada após o ensaio. Para alumina, assim como para a maioria dos materiais cerâmicos, a taxa de desgaste apresenta um comportamento de transição que depende da carga aplicada, que está associada com a mudança do modo suave 
para o modo severo (ou de fratura). A transição está ligada ao aumento na taxa de desgaste e geralmente é indicada pela evidência do início de fratura frágil da superfície [6, 7]. A taxa de desgaste que caracteriza o início do modo severo é acima de $10^{-4} \mathrm{~mm}^{3} / \mathrm{Nm}$.

A avaliação da taxa de desgaste de um material cerâmico depende de alguns fatores como velocidade de ensaio, tempo e características do ambiente. Por isso, um dos grandes obstáculos encontrados quando se decide comparar as características tribológicas de materiais diferentes é a maneira como o ensaio foi realizado. Sabe-se que existem vários tipos de equipamentos, e que cada um deles possui uma configuração diferente e estas diferenças se refletem nos resultados finais; por exemplo, haverá variação de taxa de desgaste em um mesmo material dependendo do ângulo no qual o carregamento estará sendo feito sobre o corpo de prova a ser ensaiado, e assim por diante. Assim, resultados observados na literatura devem ser analisados cuidadosamente para que não haja julgamento errado quanto às características apresentadas por determinado tipo de material.

Os resultados mais reprodutíveis encontrados utilizaram equipamentos do tipo pino-contra-disco, com ensaios realizados a seco ou com lubrificação com água. No caso de ensaios de desgaste em cerâmicas, é interessante que ambas as partes submetidas ao desgaste, o pino e o disco, sejam feitas de cerâmicas, ou seja, o disco deve ter igual ou maior dureza que o pino para que ocorra o seu desgaste [8]. A avaliação da taxa de desgaste pode ser feita medindo-se a perda de massa ocorrida após o ensaio, e aplicando-se na equação desenvolvida inicialmente por Archard [9]:

$$
\mathrm{w}=\frac{\mathrm{V}}{\mathrm{F} \cdot \mathrm{x}} \mathrm{mm}^{3} / \mathrm{Nm}
$$

na qual w é a taxa de desgaste, $\mathrm{V}$ é o volume de material desgastado, F a carga do ensaio (N), e x a distância (m). O volume $\mathrm{V}$ é relacionado com a perda de massa durante o teste e com a massa específica do corpo-de-prova.

Cerâmicas à base de alumina têm apresentado excelentes resultados tribológicos, quando comparadas a materiais cerâmicos não óxidos. Amutha Rani e cols. observaram no estudo sobre a comportamento de desgaste a úmido, que alumina apresentou menores taxas de desgaste e maior coeficiente de fricção que $\mathrm{SiC}$ e $\mathrm{Si}_{3} \mathrm{~N}_{4}$ [8]. Tal comportamento pode ter algumas explicações: a maior estabilidade térmica e química da alumina desfavorece reações triboquímicas que ocorrem com facilidade com o $\mathrm{SiC}$ e o $\mathrm{Si}_{3} \mathrm{~N}_{4}$ devido à elevada energia livre $(\Delta \mathrm{G}=-370 \mathrm{~kJ} / \mathrm{mol} \mathrm{e} \Delta \mathrm{G}=-566 \mathrm{~kJ} / \mathrm{mol}$, respectivamente), que favorecem a formação de filmes de $\mathrm{SiO}_{2}$, pouco resistentes a condições de desgaste. De acordo com os autores, foi mais fina a formação de filmes lubrificantes de trihidróxido de alumínio, como produto triboquímico da fricção do par $\mathrm{Al}_{2} \mathrm{O}_{3} / \mathrm{Al}_{2} \mathrm{O}_{3} \mathrm{e}$, portanto, gerou um maior coeficiente de fricção devido à maior facilidade de perda do filme lubrificante entre as partes. A energia livre envolvida nas reações de formação do filme lubrificante de hidróxido foi baixa $(\Delta \mathrm{G}=-26$ $\mathrm{kJ} / \mathrm{mol}$ ), sugerindo uma baixa taxa de reação da alumina com água. Assim, o principal mecanismo responsável pelo comportamento de desgaste de pares deslizantes (como $\mathrm{Al}_{2} \mathrm{O}_{3} / \mathrm{Al}_{2} \mathrm{O}_{3}$ ) é a cooperação entre interações químicas e mecânicas. No caso do desgaste a úmido da alumina, como o fator químico tem baixa influência, devido à grande estabilidade termodinâmica deste componente, é esperado que ela tenha um desempenho excelente.

\section{PROCEDIMENTO EXPERIMENTAL}

Pós de $\gamma-\mathrm{Al}_{2} \mathrm{O}_{3}$ e $\alpha-\mathrm{Al}_{2} \mathrm{O}_{3}$ com e sem aditivos $(\mathrm{MgO}$ e $\mathrm{La}_{2} \mathrm{O}_{3}$ ) sintetizados a partir do processo da decomposição térmica do acetato de alumínio - liofilização [10] e uma alumina comercial (A1000 SG, Alcoa) foram usados na preparação de pinos para serem avaliados quanto à resistência ao desgaste. As amostras preparadas apresentaram tamanho médio de partículas em torno de $41 \mathrm{~nm}$ e $54 \mathrm{~nm}$ para $\gamma-\mathrm{Al}_{2} \mathrm{O}_{3}$ e $\alpha-\mathrm{Al}_{2} \mathrm{O}_{3}$, respectivamente, e a alumina $\mathrm{A} 1000 \mathrm{SG}$ em torno de $0,3 \mu \mathrm{m}$. Os pós de alumina proveniente de acetato foram preparados a partir de um processo descrito previamente [10] que se baseou na secagem por liofilização e decomposição térmica de suspensões estabilizadas de acetato de alumínio em diferentes faixas de $\mathrm{pH}$. Este processo permitiu a preparação de pós com partículas finas, reativas e de elevada pureza. Os ensaios de desgaste foram feitos em um equipamento do tipo pino-contra-disco Plint modelo TE67, mostrado na fotografia da Fig. 1. A amostra a ser desgastada (pino) incidiu perpendicularmente sobre o disco, com a carga aplicada também na posição normal. Para os testes foi escolhido um procedimento com base na norma ASTM G99-95 [11]. Para que ocorresse o desgaste dos pinos, o disco de teste foi feito em alumina (A1000 SG, Alcoa), prensado uniaxialmente a 65 MPa e sinterizado a $1550{ }^{\circ} \mathrm{C}$. Os furos necessários à fixação no equipamento foram feitos no disco pré-sinterizado a 1000 ${ }^{\circ} \mathrm{C}$, descontada a retração da sinterização. Após a sinterização os discos foram retificados e a superfície de contato com os pinos foi polida com pasta de diamante. Todos os testes foram feitos em triplicata. Os pinos de desgaste foram construídos com uma geometria que facilitou a fixação dos mesmos no equipamento. De forma cilíndrica, apresentaram uma calota esférica na extremidade, que ficou em contato com o disco. A forma dos pinos é mostrada no esquema da Fig. 2. Os pinos foram confeccionados por prensagem uniaxial do pó em um molde de aço, com uma calota esférica, em negativo, no pistão. Todos os pinos foram sinterizados a $1600^{\circ} \mathrm{C}$ por $2 \mathrm{~h}$ ao ar, com exceção dos pinos feitos a partir dos pós de alumina comercial, que foram sinterizados a $1650{ }^{\circ} \mathrm{C}$ por $2 \mathrm{~h}$ ao ar.

Os parâmetros previamente estabelecidos para os testes e as condições de preparação dos pinos foram: carga: $32 \mathrm{~N}$, velocidade de deslizamento de 0,48 a $0,50 \mathrm{~m} / \mathrm{s}$, distância percorrida total de $3000 \mathrm{~m}$, preparação dos pinos (lavagem com acetona, secagem em estufa a $70{ }^{\circ} \mathrm{C}$, resfriamento em dessecador por $30 \mathrm{~min}$, antes da pesagem, e pesagem).

As amostras foram mantidas no dessecador até o 


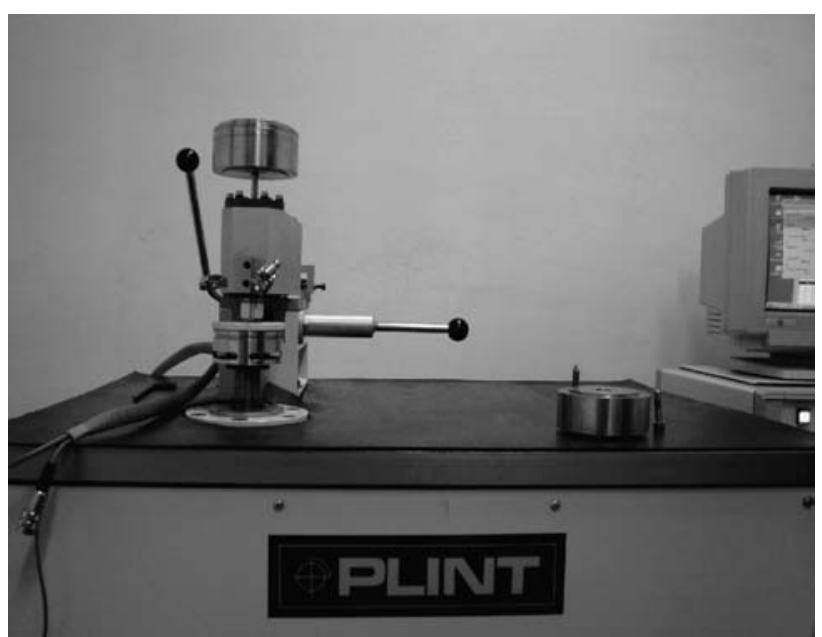

Figura 1: Equipamento de ensaio de resistência ao desgaste, do tipo pino-contra-disco.

[Figure 1: Pin-on-disk wear test equipment.]
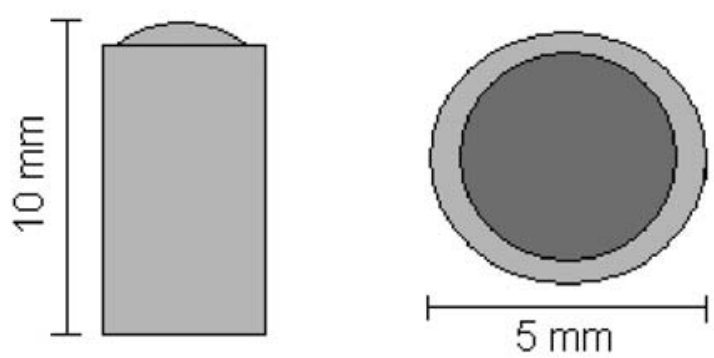

Vista Lateral

Vista Superior

Figura 2: Esquema dos pinos de desgaste.

[Figure 2: Scheme of the wear pins.]

momento do ensaio. Os resultados de coeficiente de atrito e força de atrito foram fornecidos pelo programa de controle do equipamento e foram calculados a partir dos parâmetros fornecidos pelo usuário (carga, raio, velocidade de deslizamento). A avaliação da resistência ao desgaste foi feita pela medição da perda de massa sofrida pelos pinos após os testes. Por meio deste parâmetro pôde-se medir, então, a taxa de desgaste, com base na equação A. A morfologia das regiões desgastadas dos pinos foi avaliada por microscopia eletrônica de varredura (Carl Zeiss, DSM 940 A).

\section{RESULTADOS}

A modalidade de ensaio escolhida foi o deslizamento a seco em um equipamento do tipo pino-contra-disco. As condições de ensaio seguem as orientações estabelecidas pela norma ASTM 90-95a [11] e outras fontes [1-4]. Escolheu-se, também, utilizar pinos e discos de mesmo material, ou seja, alumina, sendo os pinos confeccionados
Tabela I: Resultados obtidos nos testes de resistência ao desgaste do tipo pino-contra-disco. A taxa de desgaste medida se refere ao pino.

[Table I: Results obtained from the pin-on-disk wear tests. The measured wear rate corresponds to the pin.]

\begin{tabular}{cccc}
\hline Pino & $\begin{array}{c}\text { Coeficiente } \\
\text { de atrito } *\end{array}$ & $\begin{array}{c}\text { Força de } \\
\text { atrito }(\mathrm{N}) *\end{array}$ & $\begin{array}{c}\text { Taxa de } \\
\text { desgaste } \\
\left(\mathrm{mm}^{3} / \mathrm{Nm}\right)\end{array}$ \\
\hline$\alpha$ & 1,025 & 35,7 & $3,05 \cdot 10^{-7}$ \\
$\alpha+\mathrm{MgO}$ & 1,029 & 36,2 & $3,56 \cdot 10^{-7}$ \\
$\alpha+\mathrm{La}_{2} \mathrm{O}_{3}$ & 0,98 & 34,9 & $4,09 \cdot 10^{-7}$ \\
$\gamma$ & 1,27 & 46,6 & $1,67 \cdot 10^{-6}$ \\
$\gamma+\mathrm{MgO}_{2}$ & 1,44 & 49,3 & $4,51 \cdot 10^{-6}$ \\
$\gamma+\mathrm{La}_{2} \mathrm{O}_{3}$ & 1,43 & 44,6 & $3,99 \cdot 10^{-6}$ \\
$\mathrm{~A} 1000$ & 1,67 & 54 & $1,76 \cdot 10^{-5}$ \\
$\mathrm{~A} 1000+\mathrm{MgO} \mathrm{O} O$ & 1,55 & 49,3 & $1,36 \cdot 10^{-5}$ \\
$\mathrm{~A} 1000+\mathrm{La}_{2} \mathrm{O}_{3}$ & 1,59 & 46,9 & $2,33 \cdot 10^{-5}$ \\
\hline
\end{tabular}

* valores medios

a partir de cada composição a ser estudada e os discos, de alumina comercial. Os resultados indicam que, sob a carga aplicada, alguns pinos apresentaram baixa taxa de desgaste, principalmente os feitos a partir de pós de $\alpha$ $\mathrm{Al}_{2} \mathrm{O}_{3}$ liofilizada. Os pinos confeccionados com $\gamma-\mathrm{Al}_{2} \mathrm{O}_{3}$ mostraram bom desempenho, porém um pouco inferior aos anteriores. Os pinos confeccionados a partir de alumina A1000 SG mostraram resultados inferiores em relação às aluminas, inclusive próximos ao regime de desgaste severo. Os resultados são sumarizados na Tabela I. Estes resultados são referentes à medição após o término dos $3000 \mathrm{~m}$ de percurso.

Todos os testes com pinos feitos com $\alpha-\mathrm{Al}_{2} \mathrm{O}_{3}$ liofilizada mostraram taxa de desgaste muito baixa, abaixo do limite superior que representa o modo suave de desgaste. Isso pode significar que tais materiais apresentam resistência tãoelevada que poderiam suportar cargas bem superiores às praticadas neste trabalho, inclusive chegando aos limites encontrados em trabalhos desenvolvidos por outros pesquisadores que aplicaram cargas superiores a 70 N [1]. A seguir, são mostradas as micrografias de varredura feitas nos pinos após os testes de desgaste. As imagens são referentes à superfície da calota dos pinos. Primeiramente são apresentadas as micrografias referentes às amostras sinterizadas a partir dos pós de $\alpha-\mathrm{Al}_{2} \mathrm{O}_{3}$, as quais mostraram melhores resultados em termos de taxa de desgaste. A Figura 3 revela a superfície desgastada do pino de $\alpha-\mathrm{Al}_{2} \mathrm{O}_{3}$ liofilizada, sem aditivos, evidenciando o que foi calculado a partir do ensaio, ou seja, que houve pouco desgaste do pino.

Uma superfície lisa foi criada, e algumas regiões de arrancamento de grãos foram localizadas. Os fragmentos constitum-se em grãos arrancados da matriz. É possível observar as linhas formadas pelo deslizamento sobre o disco. Não foram observadas fraturas nas regiões de interface entre as áreas desgastadas e não desgastadas. Nas amostras de $\alpha$ - 

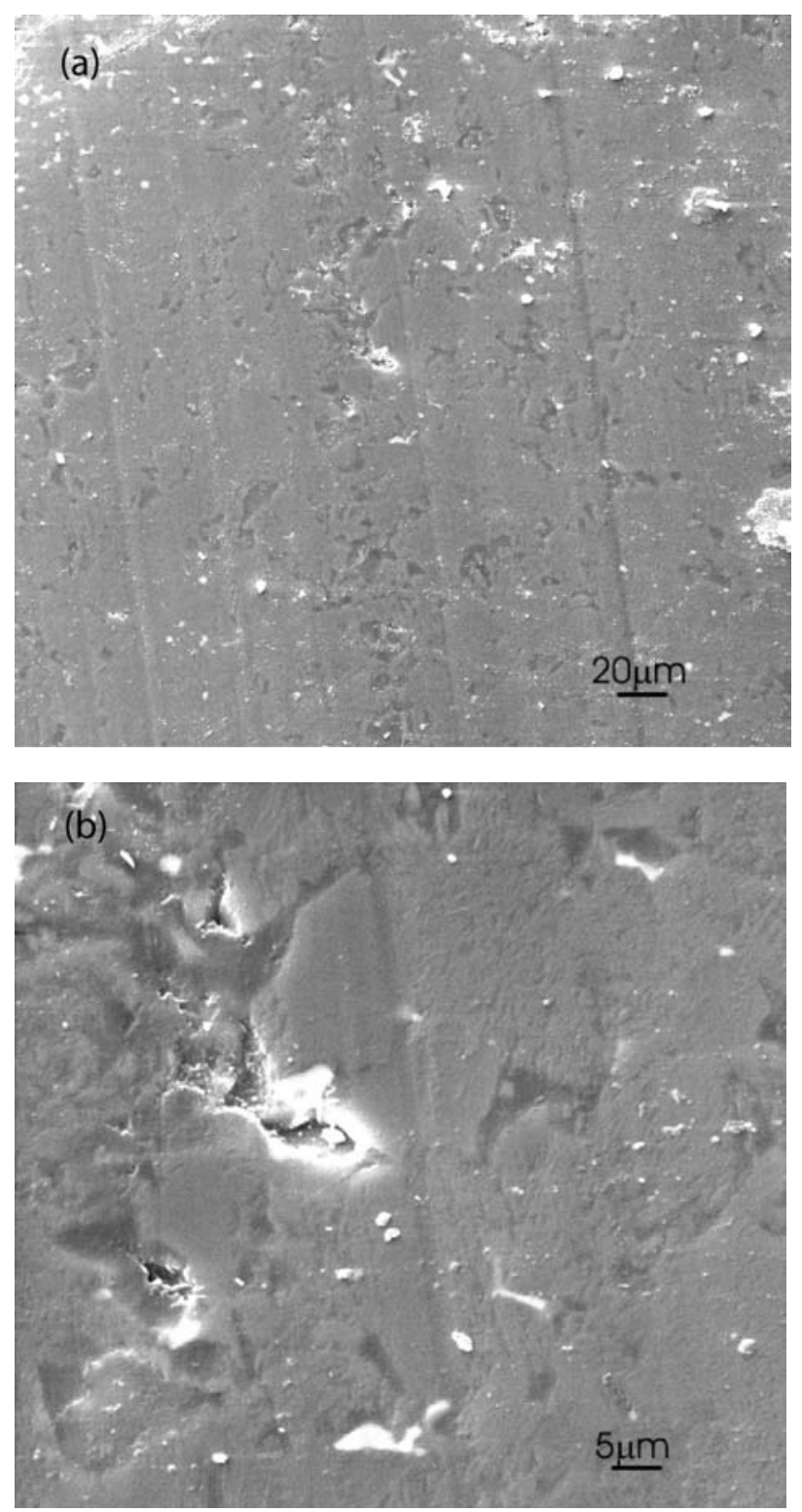

Figura 3: Micrografias de microscópio eletrônico de varredura da superfície de contato do pino de $\alpha-\mathrm{Al}_{2} \mathrm{O}_{3}$ liofilizada, sem aditivos, após ensaio de desgaste.

[Figure 3: SEM micrographs of the contact surface of the lyophilized $\alpha-\mathrm{Al}_{2} \mathrm{O}_{3}$ pin, without additives, after the wear test.]

$\mathrm{Al}_{2} \mathrm{O}_{3}$ com aditivos o comportamento foi semelhante, com valores de taxas de desgaste muito próximos. Superfícies lisas e com poucos arrancamentos também foram evidentes, como pode ser constatado nas micrografias a seguir. Na Fig. 4 os grãos foram alisados pela ação do contato das superfícies sob carga. Esta micrografia se refere à amostra sinterizada a partir do pó de $\alpha-\mathrm{Al}_{2} \mathrm{O}_{3}$ com $0,5 \%$ em massa de $\mathrm{MgO}$.

As amostras sinterizadas a partir dos pós de $\gamma-\mathrm{Al}_{2} \mathrm{O}_{3}$ liofilizadas também tiveram bom desempenho quanto à resistência ao desgaste. Contudo, maiores taxas de desgaste foram registradas neste caso e isso ficou evidente nas micrografias de varredura feitas nos pinos após ensaios. A Fig. 5 mostra uma vista geral da superfície desgastada, onde

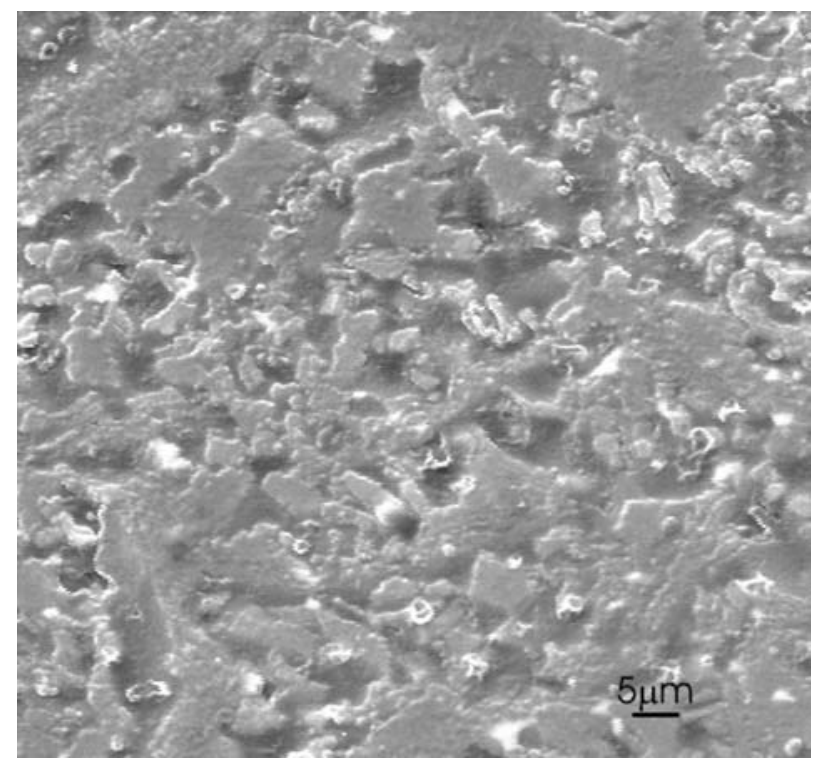

Figura 4: Micrografia de microscópio eletrônico de varredura da superfície desgastada do pino feito a partir do pó de $\alpha-\mathrm{Al}_{2} \mathrm{O}_{3}$ liofilizada, com $0,5 \%$ de $\mathrm{MgO}$, mostrando grãos alisados.

[Figure 4: SEM micrograph of the worn surface of the pin made of lyophilized $\alpha-\mathrm{Al}_{2} \mathrm{O}_{3}$ powder containing $0.5 \%$ of $\mathrm{MgO}$, showing smoothed grains.]

se pode notar a presença de grandes áreas de arrancamento de fragmentos, na direção do deslizamento no disco. Uma aproximação maior mostra detalhes dos fragmentos sobre a superfície desgastada, sem que se possam visualizar fraturas nas interfaces.

Houve uma melhora nos resultados da taxa de desgaste com a adição de magnésia e lantânio. A Fig. 6 mostra mais

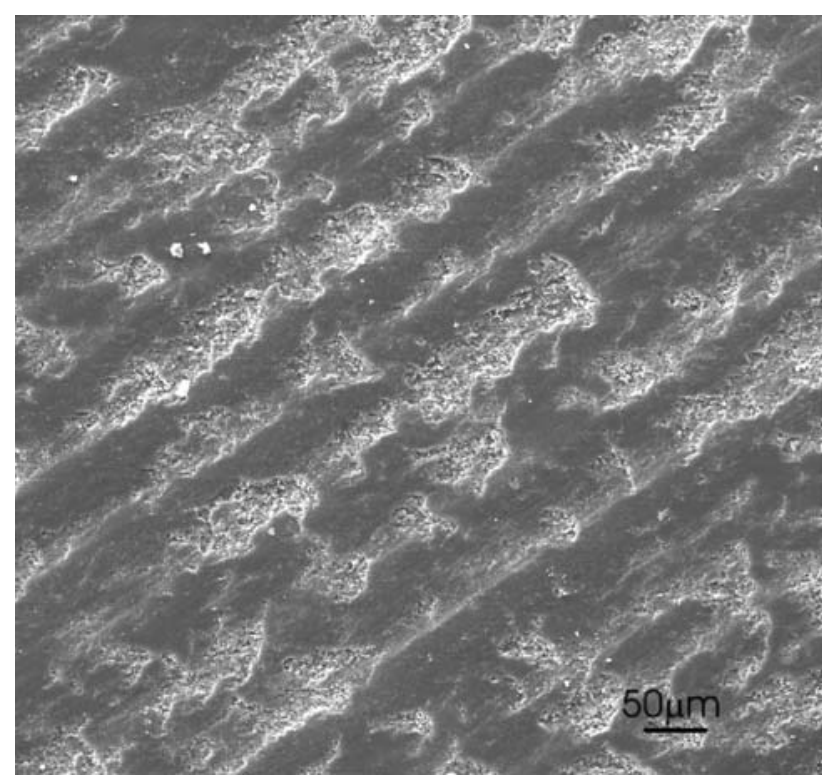

Figura 5: Superfície desgastada de pino feito a partir da sinterização de pó de $\gamma-\mathrm{Al}_{2} \mathrm{O}_{3}$ liofilizada, sem aditivos.

[Figure 5: Worn surface of a pin made by sintering lyophilized $\gamma-\mathrm{Al}_{2} \mathrm{O}_{3}$ powder, without additives.] 

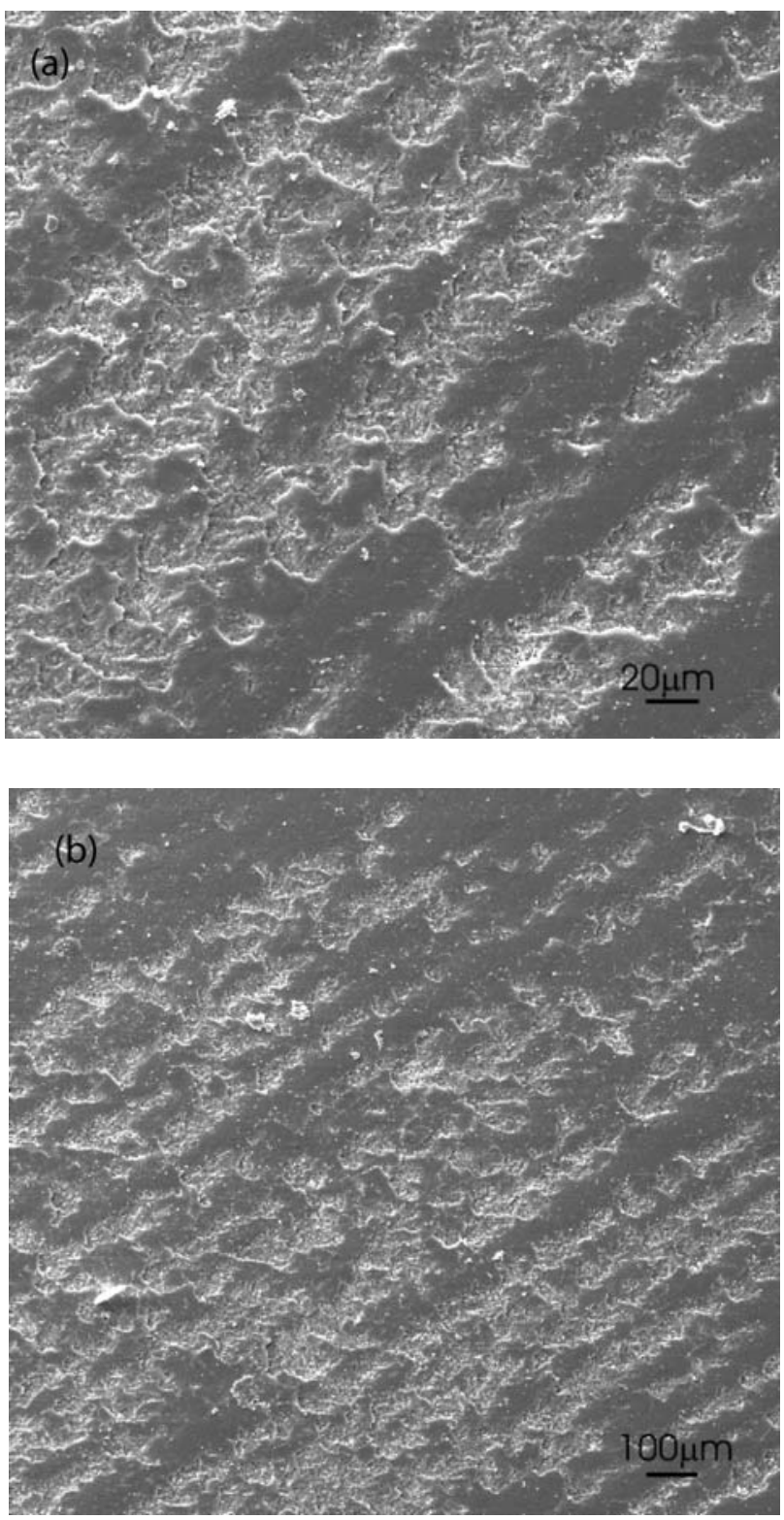

Figura 6: Micrografias de microscópio eletrônico de varredura mostrando superfícies desgastadas dos pinos de $\gamma-\mathrm{Al}_{2} \mathrm{O}_{3}$ liofilizada com $0,5 \%$ de $\mathrm{MgO}$ (a) e $0,5 \%$ de $\mathrm{La}_{2} \mathrm{O}_{3}$ (b).

[Figure 6: SEM micrographs showing worn surfaces of pins made of lyophilized $\gamma-\mathrm{Al}_{2} \mathrm{O}_{3}$ powders containing $0.5 \%$ of $\mathrm{MgO}(\mathrm{a})$ and $0.5 \%$ of $\left.\mathrm{La}_{2} \mathrm{O}_{3}(b).\right]$

dois aspectos do modo de desgaste, nos pinos sinterizados a partir de $\gamma-\mathrm{Al}_{2} \mathrm{O}_{3}$ liofilizada.

Também foram feitas, para comparar os resultados, micrografias das superfícies desgastadas dos pinos de alumina comercial, com e sem aditivos. Em geral, a A1000 SG teve o pior desempenho dentre os materiais aqui estudados, apresentando maiores taxas de desgaste em relação às aluminas obtidas pelo processo de liofilização. As micrografias também mostraram grandes diferenças, como pode ser visto na Fig. 7. Vale ressaltar que, apesar de os resultados para A1000 SG
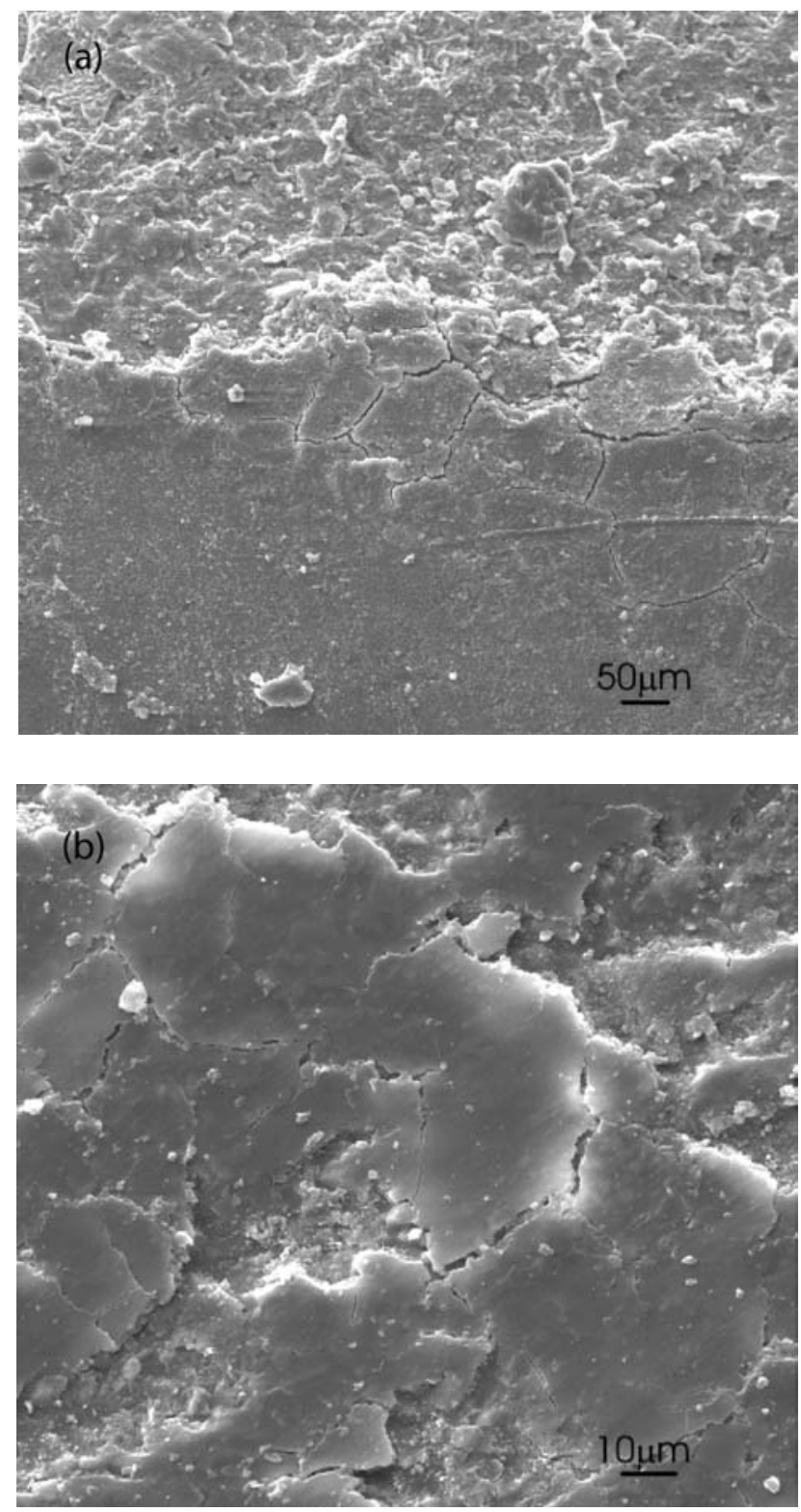

Figura 7: Micrografias de microscópio eletrônico de varredura de superfície desgastada do pino de alumina comercial mostrando interface com presença de trincas.

[Figure 7: SEM micrographs of worn surface of the commercial alumina pin, showing interfaces with cracks.]

serem inferiores aos das aluminas provenientes de acetato liofilizado, eles são considerados muito bons, de acordo com o regime de ensaio adotado $[6,7]$.

Estas imagens foram localizadas numa região de interface entre as áreas desgastada e não desgastada, e pode-se ver a presença de uma rede de trincas. Resultado semelhante foi encontrado [12] e atribuído ao ataque preferencial aos contornos de grão, delaminando e lascando a superfície, o que gera detritos que formam uma tribocamada na área desgastada. No caso da alumina comercial, este resultado 
pode estar ligado ao processo de preparação do pó, que consistiu de defloculação em $\mathrm{pH}$ 9, próximo ao ponto isoelétrico da alumina. Sabe-se que, nesta faixa de $\mathrm{pH}$, pode ocorrer a formação de fragmentos em forma de flocos, em ensaios tribológicos, e estes flocos são responsáveis pela formação da tribocamada, a qual acaba por ser delaminada formando a rede de trincas aqui observada [12]. A micrografia da Fig. 6b mostra algumas destas trincas formadas na tribocamada.

\section{CONCLUSÕES}

Os melhores resultados de resistência ao desgaste do tipo pino-contra-disco foram obtidos nos pinos sinterizados a partir dos pós de $\alpha-\mathrm{Al}_{2} \mathrm{O}_{3}$, com e sem aditivos, com taxas de desgaste da ordem de até $4 \times 10^{-7} \mathrm{~mm}^{3} / \mathrm{Nm}$. Os pinos sinterizados a partir da $\gamma-\mathrm{Al}_{2} \mathrm{O}_{3}$ apresentaram resultados intermediários, alcançando $4,5 \times 10^{-6} \mathrm{~mm}^{3} / \mathrm{Nm}$, e os resultados menos expressivos foram obtidos nos pinos de alumina comercial, com taxas de até $2,33 \times 10^{-5} \mathrm{~mm}^{3} / \mathrm{Nm}$. Contudo, mesmo estes resultados, que foram inferiores aos das aluminas provenientes de acetato de alumínio liofilizado, são considerados bons de acordo com dados da literatura. A formação da tribocamada na superfície dos pinos de alumina A1000 SG pode ser devido ao processo de defloculação em $\mathrm{pH} 9$, que gera fragmentos em forma de flocos, os quais provocam o surgimento da tribocamada.

\section{AGRADECIMENTOS}

Ao Conselho Nacional de Desenvolvimento Científico e Tecnológico (CNPq) pelas bolsas de doutorado e apoio financeiro (476382/2004-1) e à Fundação de Amparo e Pesquisa do Estado de S. Paulo - FAPESP.

\section{REFERÊNCIAS}

[1] W. M. Rainforth, J. Mater. Sci. 39 (2004) 6705.

[2] J. Zhou, S. Bahadur, Wear 181-183 (1995) 178.

[3] K. Kato, K. Adachi, Wear, 253 (2002) 1097.

[4] Adachi, K., Kato, Wear, 245 (2000) 84.

[5] W. E. Lee, W. M. Rainforth, Ceramic microstructures, Chapman \& Hall, Londres (1994).

[6] M. C. Shen, S. M. Hsu, Wear 200 (1996) 154.

[7] H. Y. Liu, S. M. Hsu, Wear 195 (1996) 169.

[8] D. Amutha Rani, Y. Yoshizawa, H. Hyuga, K. Hirao, Y. Yamauchi, J. Eur. Ceram. Soc. 24 (2004) 3279.

[9] J. F. Archard, J. Appl. Phys. 24 (1953) 981.

[10] E. Fagury-Neto, Tese de Doutorado, "Preparação por liofilização e sinterização de pós nanométricos de aluminas", Departamento de Engenharia de Materiais, Universidade Federal de S. Carlos, S. Carlos (2005).

[11] ASTM G99-95A, Standard test method for wear testing with a pin-on-disc apparatus (1997) 5.

[12] S. Novak, M. Kalin, Trib. Lett. 17 (2004) 4.

(Rec. 12/03/2007, Ac. 18/08/2007) 